\title{
Coping among Students: Development and Validation of an Exploratory Measure
}

\author{
Emilie Boujut ${ }^{1}$, Marilou Bruchon-Schweitzer ${ }^{2}$, Stephan Dombrowski ${ }^{3}$ \\ ${ }^{1}$ University Paris Descartes, Paris, France \\ ${ }^{2}$ University Bordeaux Segalen, Bordeaux, France \\ ${ }^{3}$ Newcastle University, Newcastle, UK \\ Email: emilie.boujut@parisdescartes.fr
}

Received February $10^{\text {th }}, 2012$; revised April $2^{\text {nd }}, 2012$; accepted June $3^{\text {rd }}, 2012$

\begin{abstract}
Students are a very specific population as regards their manner to cope with stress. A coping questionnaire for students was developed and administered to 1100 French students at the beginning of the term (T1). Principal Component Analysis of responses, followed by varimax rotations, yielded three factors accounting for $50.5 \%$ of the total variance. Factors were identified as seeking social support, avoidance/emotion-focused coping and festive-addictive coping. Associations were observed between scores on these factors and a general coping scale (WCC-R), personal variables measured at the same time (T1), neuroticism, self-esteem, substance use, and four stress factors, as well as variables measured at the end of the term (T2), somatic symptoms, depressive symptoms, eating disorders, and life satisfaction. It would be very interesting to develop the students' personal competencies, so that they learn how to adopt functional strategies of coping rather than the harmful kind.
\end{abstract}

Keywords: Coping; Students; Stress; Validation; Addictions; Health

\section{Introduction}

The theory of "emerging adulthood" conceptualizes the developmental characteristics of people aged 18 to 25 (Arnett, 2000). Although previous research has contributed significantly to our understanding of emerging adulthood (Erikson, 1968; Keniston, 1971; Levinson, 1978), the key characteristics of this life period have changed considerably since the $1970 \mathrm{~s}$, when the theory was developed. Demographics such as age of marriage and parenthood have profoundly shifted in industrialized societies; whereas before the 1970 s, young adults entered marriage and parenthood in their early $20 \mathrm{~s}$, these roles are now more commonly entered into during the late 20 s and early 30 s. Young adults often spend the period stretching from late teens to mid-twenties experimenting in their love and work lives (Arnett, 2005) and this might be particularly true for those who choose to continue schooling at the college or university level. Whereas emerging adulthood was previously considered to be covered by other developmental stages, developmental psychologists now consider this period to be well-defined and unique stage, with young adults passing through both a developmental and an educational transition (Boujut, BruchonSchweitzer, \& Rascle, 2004). This paper thus focuses on some of the problems that university students frequently face during 'emerging adulthood'; how they perceive these problems at the beginning of a term, and the effect of these variables on three outcomes: somatic, mental health and health-related behaviors.

Students' stress is considered to be a transactional process between the new and stressful situation they have to face (e.g. beginning the first year of university) and their personal and social resources. These university students are considered to be in the last period of transition before adult life (Towbes \&

*The authors report no conflicts of interest.
Cohen, 1996), and their psychological and physical discomfort can manifest itself in various ways, including mood, sleep and eating disorders. Although there has been little research proving pathology, it appears that many students present discrete sub symptomatic forms of discomfort that are seldom the subject of consultation. In a recently conducted study, approximately $15 \%$ of students indicated having had suicidal ideas, the second leading cause of mortality (after road accidents) among individuals aged 18 - 24 years, and $30 \%$ presented depressive symptomology during the previous 12 months (Lafay, Manzanera, Papet, Marcelli, \& Senon, 2003). Other risk factors include the consumption of psychoactive substances, which tends to increase over time, with alcohol consumption consultations planned to become an integral part of medical visits to first year students (Wauquiez, 2006).

Despite the reporting of many symptoms including somatic (e.g. tiredness, headaches, backaches), psychological (e.g. depression, suicidal tendencies), and behavioral disorders (e.g. eating habits, addictive behaviors) among first year students, very few studies have focused on students' coping and health (Boujut et al., 2004). Grebot and Barumandzadeh (2005) examined the perception of stress and the coping strategies that were adopted by students during their first year and noted an increase in the perception of stress (in terms of threat) between entry and 2 months, after which students would begin to more realistically understand the requirements of university. The students would, at this time, adopt dysfunctional coping strategies, such as drinking, smoking, or taking drugs. These authors suggested that it would be beneficially to carry out research on the coping strategies that are likely to develop anxiety-depressive disorders or aggravate psychic stress at a later stage. Other research reports have found that problem-centred coping, emotional coping, avoidance, and neglecting to seek social support, predicts 
less positive mental health in students (Dunkley, Zuroff, \& Blankstein, 2003; Hatchett \& Park, 2004; Stewart et al., 1997). Dunkley et al. (2003) report that the absence of active coping, as well as the recourse to emotional coping and distraction, increase the somatic symptoms of students.

In a longitudinal study of first years students, Halamandaris and Power (1997b) evaluated the coping strategies most frequently used during the first two weeks of entry, as well as the issue of adaption at the end of the semester. The strategy of seeking social support was predictive of good adaption. Vollrath (1998), in a study of the transactional model of addiction, demonstrated that students who smoke use more dysfunctional coping strategies (like denial, distraction, emotional coping and addictive coping) than non-smokers. She explains that smokers often use tobacco to regulate their negative emotions, rather than using functional strategies like problem-centred coping or seeking social support. This strategy tends to increase the number of unresolved problems the students face, and thus their stress. This phenomenon has also been demonstrated in other populations of smokers (Wills, 1986; Wills \& Shiffman, 1985).

Links between coping and eating disorders have been highlighted in previous research as well. Emotional coping and problem-centred coping have been found to be correlated positively and negatively, respectively, with the intensity of compulsive eating symptoms among 164 students (Janzen, Kelly, \& Saklofske, 1992). Similar results were found with regard to emotional coping and avoidance coping among 150 students (Janzen et al., 1992). Avoidance coping was also positively correlated with avoiding food behaviors in a study of 49 students (Mayhew \& Edelmann, 1989). The results of comparative studies (with a control group) are similar: avoidance coping appears more prominently among students who compulsively eat than others (Paxton \& Diggens, 1997). The same result was found when comparing anorexic students with healthy students (Mayhew \& Edelmann, 1989). Finally, it has been shown that students who are compulsive eaters use no more avoidance coping strategies, or emotional coping strategies, than they use problem-centred coping strategies (Mayhew \& Edelmann, 1989).

In this paper, we consider coping in a population of students, paying attention to the situational demands they encounter using the concepts of primary and secondary appraisal, as well as coping strategies. We are particularly interested in two distinct approaches to stressors: 1) how people react to normal situations of stress in terms of coping style; and 2) how people react to specific situations in terms of coping status.

Since the 1980 s, many coping questionnaires have been developed that have led to the discovery of various dimensions of coping. The general consensus within the field is that there are two meta-strategies of coping (Lazarus \& Folkman, 1984): 1) problem-focused coping (e.g. problem solving, conceptualising, minimising effects); and 2) emotion-focused coping (e.g. emotional responses, avoidance, guilt, emotional experience). Of the 13 studies identified by Endler and Parker (1990) in their critical evaluation of the multidimensional assessment of coping, 9 studies identified these two dimensions as being distinct components of coping.

In studies of coping among student populations, most researchers seem to use generic, validated, and widely used tools. Unfortunately, a number of these tools such as the Coping Strategies Questionnaire [CSQ (Roger, Jarvis, \& Najarian, 1993)], the Coping Resource Inventory (Hammer, 1988), the Cope questionnaire (Carver, Scheier, \& Weinbtraub, 1989) and the Coping Inventory for Stressful Situations [CISS (Endler \& Parker, 1999)] are used without clearly differentiating coping traits in contrast to coping states. These scales, which ultimately measure a coping style, approach coping as if it is a specific and transient transactional process, but this is only true insofar as one's coping style is created in response to normal situations of stress. In other words, the questionnaires may simplify coping to a construct rather than acknowledging the way in which coping can vary in terms of style and state. Many misunderstandings presently exist between these two aspects of coping because they are not always clearly defined or distinguished.

With regard to the evaluation of coping in student populations, a second concern is that the wording of items within questionnaires is not always adequately clear or catered for the target population. However, there is at least one coping scale that has been designed specifically for a student population (Allison, Adlaf, \& Mates, 1997). This coping scale includes 19 items, and consists of five subscales: deviant coping (e.g. drinking alcohol, smoking cigarettes or cannabis), passive coping (e.g. sleeping, listening to music, eating, watching TV), destructive coping (e.g. seeking affiliation to a gang), withdrawal/drain (e.g. crying, not eating), and affirmative action (e.g. participating in sports). Allison et al. (1997) note that the constellation of behaviours that characterise deviant coping and destructive coping are similar to the concept of problem behavior (as outlined in the Theory of Social Deviance, cf. Jessor, Chase, \& Donovan, 1980). Allison et al.'s questionnaire clearly highlights the specific behaviors exhibited by young people to cope with stress (noted above as examples of coping activities). The factors "deviant coping", "destructive coping", and "affirmative action" seem particularly relevant for the current study as these were shown to be unique for first year students, as compared to other populations. These factors do not exist in general coping scales: the Cope questionnaire is the one to evaluate substance consumption as a coping strategy, but does so with only one item. This scale needs to be validated in order to know the psychometric properties involved and the implications of coping factors on issues like health and academic performance. The unique personal and social background in which students encounter stress, and the need for questionnaires to be context appropriate underscores the need for empirical studies to better understand the responses and coping strategies of students.

\section{Aims}

The aim of the current study is to extend research in the area of coping within the student population, by adapting relevant measures to the French student population and by addressing scale validity. We seek to understand the various coping strategies that are used by students to cope with stress, differentiating between coping style and state. Secondly, the aim of this study is to explore links between coping and students' health.

In order to achieve these aims, the number of subjects in the validation population has to be at least 10 -fold the number of items being used, according to Kline's criteria (Kline, 1993). Kraener and Thiemann (1987) give Statistical Power Tables to estimate the minimum sample size necessary given the number of variables and the type of statistical calculation required.

\section{Method}

\section{Sample}

An initial series of interviews was conducted with 40 first 
year university students (20 male and 20 female) in France. The mean age of participants was $18.7(\mathrm{SD}=1.3)$.

Subsequently, a questionnaire was administered to 1100 additional students (400 male, 700 female), of which 556 continued to complete a follow-up questionnaire (153 male, and 373 female). Of the original sample, the mean age was 18.7 (SD = 1.3). There was a significant difference between participants dropping out of the study and those completing in terms of gender $\left(\mathrm{Chi}^{2}=18.5, p<.001\right)$, with completers more likely to be female.

The decrease in the number of participants between T1 and T2 seems to be partially accountable to the difficulty encountered when seeking to contact the original participants by telephone, and also non-response by those who were provided the opportunity to complete the $\mathrm{T} 2$ questionnaire by email or post.

\section{Procedure}

One-on-one interviews were conducted with 40 French students in order to inform the questionnaire-development process. In- terviews were transcribed and data was analysed using thematic analysis leading to the development of 33 distinct response cate- gories which subsequently informed the development of a 33 item coping questionnaire (the Students' Coping Scale).

This questionnaire was administered to 1100 French students at the beginning of the academic year (T1). At this time, the students also completed questions to assess neuroticism, selfesteem, general perceived stress and coping strategies.

Six months later (T2), the same students were invited to respond to the follow-up questionnaire. This questionnaire was conducted 2 - 3 weeks before exams and completed by 556 $(50.5 \%)$ students whose data was analysed in this paper. There is no difference in terms of sex and age between students lost between T1 and T2 and others (Table 1).

\section{Measures}

Neuroticism, one of the factors of the Five Factors Model, was evaluated by the Neuroticism scale of the NEO-PI-R (Costa \& Mc Crae, 1985), comprising of 48 items that have been validated in France (Rolland, Parker, \& Stumpf, 1998).

Self-esteem was assessed with the Rosenberg Self-Esteem Scale (Rosenberg, 1969). This 10 -item scale is the most widely used scale within young adult and adolescent populations.

Substance use was assessed with the ASSIST (Alcohol, Smoking and Substance Involvement Screening Test; WHO ASSIST Working Group, 2002). Only items concerning alcohol, tobacco and cannabis were used and specific scores were calculated for each substance.

Table 1.

Comparison of demographics between study dropouts (T1) and completers $(\mathrm{T} 1+\mathrm{T} 2)$.

\begin{tabular}{ccccc}
\hline & $\begin{array}{c}\mathrm{T} 1 \text { only } \\
\mathrm{N}=554\end{array}$ & $\mathrm{~T} 1+\mathrm{T} 2$ & & \\
& $\mathrm{~N}=556$ & $\mathrm{~F}^{2} \mathrm{Chi}^{2}$ & $P^{1}$ \\
\hline Gender & & & 18.574 & $>.001$ \\
Men & $61 \%$ & $47 \%$ & & \\
Women & $39 \%$ & $53 \%$ & & \\
Age & $18.8 \pm 1.4$ & $18.4 \pm 1.1$ & 14.206 & $>.001$ \\
\hline
\end{tabular}

Stress was evaluated with the Freshman Stress Questionnaire (FSQ Boujut \& Bruchon-Schweitzer, 2009), which measures four factors based on 17 items: Academic Stress (e.g. academic failure), University Dysfunctions (e.g. poor organization of university), Feelings of Loneliness (e.g. anonymity of campus), and Problems with Close Relations (e.g. sentimental problems).

Coping was also evaluated by the French adaptation of the Ways of Coping Checklist-Revised (WCC-R; Vitaliano, Russo, Carr, Maiuro, \& Becker, 1985). The French version is a 27 -item scale that measures three coping factors: problem-focused coping, emotion-focused coping, and social support seeking (Bruchon-Schweitzer, Cousson, Quintard, Nuissier, \& Rascle, 1996).

Physical Health was assessed using the subscale "somatisation" of the Psychosomatic Index of the Symptom Checklist 90 (Derogatis, 1994), which consists of 12 items.

Depression was assessed by the Beck Depression InventoryShort Form (Beck, Rial, \& Rickles, 1974), which consists of 13 items assessing the perceived severity of some depressive symptoms (affective, cognitive, vegetative) from 0 to 3 . A score of 5 or above is considered by many authors to be a cut-off that differentiates clinically depressed subjects (Beck, Steer, \& Brown, 1996).

We used the 4-item Subject Well-Being Scale (Diener, 1984; Diener, Emmons, Larsen, \& Griffin, 1985) in order to assess the wellbeing of the students.

Eating Disorders were evaluated with the Eating Attitude Test-26 (Garner \& Garfinkel, 1979) which measures a global score and three factors: restrictive behavior, bulimia and oral control. This is one of the most widely used standardised measures of symptoms and concerns that are characteristic of eating disorders (Garner, Olmsted, Bohr, \& Garfinkel, 1982).

All of the aforementioned scales (i.e. Neuroticism, Self-esteem, Stress, Coping, Physical Health, Depression, Wellbeing, and Eating Disorders) have satisfactory psychometric properties.

\section{Analyses}

To explore the dimensionality of the stress questionnaire, a Principal Component Analysis (PCA) was performed on the answers of all T1 students $(n=1110)$. We then performed Pearson product-moment correlations between the identified stress factors and variables evaluated at $\mathrm{T} 1$ in order to assess the concurrent validity of the stress factors. Finally, we used multiple regressions between stress factors and variables evaluated at T2 to establish the predictive validity of the stress questionnaire. All statistical analyses were performed with SPSS.

\section{Results}

\section{Construct Validity}

Conducting PCA analysis revealed a three-factor structure (Table 2). The first factor was found to express the search for social support, and is similar to a factor from the WCC-R ("I seek help to overcome this problem"). We call Factor 1 seeking social support. Factor 2, which we call avoidance/emotional coping, consists of the individual using behavioral strategies to cope with stress and to regulate their emotional reaction to stress. In this regard, the individual who avoids emotion-focused coping may seek to recover a more positive emotional state through behavioral activities (e.g. eating pleasant foods, watching television). Factor 3 we call festive addictive coping, and this kind of coping strategy includes any consumption of 
Table 2.

Students' coping scale $(\mathrm{N}=1110)$.

\begin{tabular}{|c|c|c|c|}
\hline & Factor 1 & Factor 2 & Factor 3 \\
\hline$\%$ Variance explained & $14.7 \%$ & $14.4 \%$ & $13.7 \%$ \\
\hline Cronbach & .75 & .68 & .60 \\
\hline
\end{tabular}

Items

6. Je parle de mes soucis à des proches (I talk to my relatives about my worries). 81

17. Je demande des conseils à d'autres personnes (I ask for advice from others). 75

27. Je demande de l'aide pour surmonter ce passage (I ask for help to overcome problems). $\quad .77$

12. Je garde mes problèmes pour moi (I keep my problems to myself). $\quad-.62$

5. Je mange plus que d'habitude (I eat more than usual).

10. Je mange des choses qui me font vraiment plaisir (I eat things that give me pleasure). .67

31. J'ai envie de pleurer (I want to cry).

7. Je regarde la TV (I watch TV).

25. Je n'arrive pas à penser à autre chose (I can’t think of anything else).

11. Je dors plus que d'habitude (I sleep more than usual).

26. Je ressens le besoin d'écrire (I feel the need to write).

19. Je bois avec des amis (I drink with friends).

4. Je sors, je m'amuse, je fais la fête (I go out, have fun, I celebrate).

20. Je fume un joint (I smoke a joint).

16. Je fume des cigarettes (I smoke cigarettes).

1. Je vois des amis pour me changer les idées (I see friends to help me change my focus).

psychoactive substances. Festive addictive coping can be repetitious and done within a seemingly celebratory environment (e.g. "I drink with friends"). The percentages of explained variance is satisfactory $(14.7 \%, 14.4 \%, 13.7 \%)$. In contrast, for the questionnaire, the alphas are questionable for Factors 2 and $3(.75, .68, .60)$.

\section{Convergent Validity}

Product-moment correlations were calculated between specific coping scores on each factor used in the students' coping scale and the three general factors of the WCC-R (Table 3). The specific and general factors of seeking social support were correlated. In addition, we observed a significant relationship between the "emotion-focused coping" of the general scale and avoidance/emotional coping in the specific scale. There were not significant relationships between festive addictive coping and the three factors in the general scale.

\section{Concurrent Validity}

Product-moment correlations were calculated between specific coping scores on each factor and the other variables measured at T1 in the 1100 students (see Table 4): SCS, Neuroticism (NEO-PI), Self-esteem (Rosenberg's Scale), and Freshman Stress Questionnaire (FSQ). Only avoidance/emotionfocused coping on the student's coping scale was significantly correlated with neuroticism (positively), self-esteem (negatively), and the four freshman stress factors (positively). Only
Table 3.

Pearson product-moment correlations between student's coping scale and general coping factors at $\mathrm{T} 1(\mathrm{n}=1110)$.

\begin{tabular}{lccc}
\hline & $\begin{array}{c}\text { Seeking social } \\
\text { support }\end{array}$ & $\begin{array}{c}\text { Avoidance/ } \\
\text { emotional } \\
\text { coping }\end{array}$ & $\begin{array}{c}\text { Festive-addictive } \\
\text { coping }\end{array}$ \\
\hline Convergent validity (T1) & $.15^{*}$ & -.08 & .03 \\
Problem-focused coping & -.11 & $.31^{* * *}$ & -.11 \\
Emotion-focused coping & $-.16^{* * *}$ & .07 & $.14^{*}$ \\
\hline Social-support seeking & $.66^{*}$ & & \\
\hline
\end{tabular}

Note: ${ }^{* * *} p<.001 ;{ }^{* *} p<.01$.

festive-addictive coping on the student's coping scale was significantly correlated with substance use (alcohol, tobacco, cannabis).

\section{Predictive Validity}

Partial regression coefficients $(\beta)$ were calculated between the three students' coping scale measured at T1 and relevant outcomes measured at T2 (Table 5). Seeking social support at T1 was negatively associated with depression and positively with life satisfaction at T2. Avoidance/emotion-focused coping at T1 was associated negatively with life satisfaction and positively with somatic symptoms, depression and eating disorders at T2. Festive addictive coping was not significantly associated with these outcomes. 
Table 4.

Pearson product-moment correlations between student's coping scale and at $\mathrm{T} 1(\mathrm{n}=1110)$.

\begin{tabular}{lccc}
\hline & $\begin{array}{c}\text { Seeking social } \\
\text { support }\end{array}$ & $\begin{array}{c}\text { Avoidance/ } \\
\text { emotional } \\
\text { coping }\end{array}$ & $\begin{array}{c}\text { Festive- } \\
\text { addictive } \\
\text { coping }\end{array}$ \\
\hline Concurrent validity (T1) & -.06 & $.45^{* * *}$ & -.02 \\
Neuroticism & .09 & $-.22^{*}$ & .03 \\
Self-esteem & .05 & .07 & $.58^{* * *}$ \\
Tobacco use & -.04 & .07 & $.49^{* * *}$ \\
Alcohol use & -.02 & .04 & $.51^{* * *}$ \\
Cannabis use & .09 & $.32^{* * *}$ & -.07 \\
Academic stressors & -.03 & $.21^{*}$ & -.07 \\
University dysfunction & -.03 & $.29^{* *}$ & .01 \\
Loneliness \\
problems with close relations & .04 & $.36^{* * *}$ & .02 \\
\hline
\end{tabular}

Note: ${ }^{* * *} p<.001 ;{ }^{* *} p<.01$.

Table 5.

Multiple Regressions Analysis between the stress factors and criteria of Emotional and Physical Adjustment evaluated at T2 $(\beta)(n=556)$.

\begin{tabular}{lccc}
\hline & $\begin{array}{c}\text { Seeking } \\
\text { social } \\
\text { support }\end{array}$ & $\begin{array}{c}\text { Avoidance/ } \\
\text { emotional } \\
\text { coping }\end{array}$ & $\begin{array}{c}\text { Festive- } \\
\text { addictive } \\
\text { coping }\end{array}$ \\
\hline Predictive validity (T2) & & & \\
Somatic symptoms (SCL-90) & .023 & $.263^{* * *}$ & .056 \\
State-Depression (BDI-SF) & $-.166^{* * *}$ & $.312^{* * *}$ & -.005 \\
Eating disorders (EAT-26) & -.002 & $.196^{* * *}$ & -.015 \\
Life satisfaction (Diener Scale) & $.104^{*}$ & $-.195^{* * *}$ & .023 \\
\hline
\end{tabular}

\section{Discussion}

Having applied a newly developed students' coping questionnaire to a French population, we found three factors to be of relevance: seeking social support (e.g. "I talk about my worries with relatives"), avoidance/emotion-focused coping (e.g. "I want to cry") and festive addictive coping (e.g. "I drink with friends"). The percentages of explained variance and Cronbach's alpha were satisfactory, but the coefficient of internal consistency of the third factor was weak.

Two coping strategies that are highlighted here are comparable to those that have been isolated from other populations: seeking social support and emotion-focused coping (Folkman, Lazarus, Dunkel-Schetter, DeLongis, \& Gruen, 1986). We have used two research instruments: a general questionnaire on coping (the WCC-R) and an original questionnaire on coping for students: the students' coping scale. The factors of emotionfocused coping and seeking social support were common to both questionnaires. Problem-focused coping only appeared in the WCC-R and not in our specialised questionnaire, undoubtedly because the discussions that were carried out in order to create items were held at the beginning of the school year and not during examinations. Seeking social support was expressed similarly in both questionnaires. Emotion-focused coping was expressed differently in our questionnaire (eating more, sleeping more, watching television, eating pleasant foods) and the WCC-R (hoping a miracle would happen, trying to forget the whole thing, blaming myself, etc.). The kinds of avoidance/ emotion-focused coping strategies that we used were ca- tered to the population in consideration. A similar approach was taken to festive-addictive coping, where we chose to express this strategy with strategies that are relevant to our target population: partying, drinking with friends, smoking joints, smoking cigarettes.

The development and validation of specific coping questionnaires for students can help us to more precisely study the factors determining the populations' coping from various adaptive or dysfunctional approaches (Vollrath, 1998). The strategies that have been discussed here uncover many significant effects on various issues, particularly dysfunctional effects as regards the avoidance/emotion-focused coping strategies. In our study, as in previous research, adopting emotion-focused coping (as in the WCC-R) predicted more depressive and somatic symptoms, eating disorders and less life satisfaction at the end of the year (Janzen et al., 1992). As in previous studies, the search for social support is a coping strategy that decreases state-depression and increases life satisfaction. It is probably the case that having friends or a close and attentive family helps students to feel supported in times of stress (Halamandaris \& Power, 1997a). The festive-addictive coping has no functional or dysfunctional effects, but correlates with substance use without seeming to have consequences on physical or mental heath among students during the first year. It is possible that this factor has a longterm effect on health, as substance use often predicts health problems among young adults, but this effect would certainly manifest at a much later point in time (Vollrath, 1998).

In summary, our study supports previous research with regard to the effect of more traditional strategies of coping (Stewart et al., 1997). Emotional-avoidance coping consists of trying to avoid a flooding of emotional tension by diverting attention from the stressful situation toward satisfying substitutes (e.g. eating more or pleasurable foods, sleeping, watching TV). This strategy is sometimes effective (at least temporarily) as it reduces emotional tension (Paxton \& Diggens, 1997), but in our sample its effects were clearly dysfunctional. It corresponds both to an attempt to avoid stressful situations and problems (it is moderately associated with the emotional- avoidance coping of the WCC) and with the seeking of imme- diate and shared pleasures. Consuming food or other substances in the face of adversity seems to be a very specific strategy that has parallels with addiction, even if this consumption does not involve psychoactive substances (Ball \& Lee, 2002). With regard to "festive-addictive coping", our findings were unexpected. Psychoactive substance consumptions are not associated in the avoidance/emotion-focused coping but are associated to having fun with friends. This suggests that consumption is used in a festive mode, and that it is not unhealthy when we are looking only at the students' lives in their first year.

Among the coping factors of this specific scale, avoidance/ emotion-focused coping, one behavioral strategy appears to be particularly relevant to first year students: the recourse to "festive addictive" coping. This underlines the originality of the new tool we have developed. The context in which first-year students live, which involves both developmental and educational transition, seems to be one in which students experience rather specific states of stress (e.g. academic stress, loneliness, stress relating to the dysfunctions of the university itself). In order to face these states of stress, certain students will adopt a festive-addictive coping strategy (Vollrath, 1998), which will provide short-term satisfaction and relief from stress. This is 
compatible with the Theory of Self-Medication (Khantzian, 1985), in which behaviors like smoking or drinking are able to have a regulating function on emotion. They seem to be related more to the quest for social support than an unhealthy addictive strategy, given the correlation that was found between the factor of "search for social support" of the WCC and that of festive coping. This type of strategy is a good illustration of how the feeling of freedom can improve the students' perception of stress in the beginning of their first year-during a period during in which the students' relationships to their parents change, and when the university institution itself is not perceived to be sufficiently "framing" (i.e. it does not provide the students with a satisfying amount of structure). This first year of study coincides with a period of transition, in which students can explore their identity, and try new experiences (Arnett, 2004). It is particularly interesting that coping responses are seemingly characteristic of the age group that was sampled (e.g. changing dietary habits, sleep patterns, and self-medicating). In all general coping scales, we found only one item which concerned substance use as a strategy (Carver et al., 1989), and this item is a factor and was not associated with other behaviors. Moreover, only one specific students' coping scale (Allison et al., 1997) is described in literature, but it has not been statistically validated. This students' coping scale was used when developing the study described in this report, as it links specific behaviors to the coping strategies used by young adults in times of stress.

In conclusion, further effort should be made with regard health education, with the aim of helping students to modify their behaviors in times of stress. We have emphasized the importance of certain behaviors as avoidance strategies (e.g. to eat more or sleep more than usual), and have drawn attention to the risks that can be incurred through these behaviors. The stress that is generated by entering an institution with complex rules and in which students may feel anonymous requires these students to undertake various efforts of adjustment, and these coping strategies can be more or less successful. The adoption of an avoiding strategy, rather than a vigilant strategy, can lead students to develop depressive affects and to adopt unhealthy eating habits. It would be very interesting to develop the students' personal competencies, so that they are learning how to adopt functional strategies of coping (i.e. coping centred on the problem) rather than of the harmful kind (e.g. emotionalavoidance coping). Certain environmental and sometimes individual conditions can limit the choice of coping strategy that the students adopt, and encourage the most vulnerable of students toward the adoption of avoidance strategies and risk behaviors. We know that the family unit and university personnel can play an important and beneficial role in helping students cope with this transitory period (Boujut, Koleck, BruchonSchweitzer, \& Bourgeois, 2009). Similarly, health professionals assigned to universities could play an important role as regards the prevention, tracking and treatment of student stress, if adequate means of conducting this kind of work were available.

\section{REFERENCES}

Allison, K. R., Adlaf, E. M., \& Mates, D. (1997). Life-strain, coping and substance use among high school students. Addiction Research, 5, 251-273. doi:10.3109/16066359709005265

Arnett, J. J. (2000). Emerging adulthood: A theory of development from the late teens through the twenties. American Psychologist, 55,
469-480. doi:10.1037/0003-066X.55.5.469

Arnett, J. J. (2004). Adolescence and emerging adulthood: A cultural approach. Upper Saddle River, NJ: Prentice-Hall.

Arnett, J. J. (2005). The developmental context of substance use in emerging adulthood. Journal of Drug Issues, 35, 235-253. doi: $10.1177 / 002204260503500202$

Ball, K., \& Lee, C. (2002). Psychological stress, coping, and symptoms of disordered eating in a community sample of young australian women. International Journal of Eating Disorders, 31, 71-81. doi:10.1002/eat.1113

Beck, A. T., Rial, W. Y., \& Rickles, K. (1974). Short form of depression inventory: Cross-validation. Psychological Reports, 34, 1184 1186.

Beck, A. T., Steer, R. A., \& Brown, G. K. (1996). Inventaire de Dépression de Beck-2ème édition. ECPA.

Boujut, E., \& Bruchon-Schweitzer, M. (2009). A construction and validation of a freshman stress questionnaire: An exploratory study. Psychological Reports, 104, 680-692. doi:10.2466/pr0.104.2.680-692

Boujut, E., Bruchon-Schweitzer, M., \& Rascle, N. (2004). Stress and health in a student population: A transactional model perspective. Psychology and Health, 19, 25-26.

Boujut, E., Koleck, M., Bruchon-Schweitzer, M., \& Bourgeois, M. (2009). La santé mentales chez les étudiants: Enquête auprès d'une cohorte de 556 étudiants de 1ère année. Annales Médico-Psychologiques, 167, 662-668. doi:10.1016/i.amp.2008.05.020

Bruchon-Schweitzer, M., Cousson, F., Quintard, B., Nuissier, J., \& Rascle, N. (1996). French adaptation of the way of coping checklist. Perceptual \& Motor Skills, 83, 104-106. doi:10.2466/pms.1996.83.1.104

Carver, Scheier, M. F., \& Weinbtraub, J. K. (1989). Assesing coping strategies: A theoretically based approach. Journal of Personality \& Social Psychology, 56, 267-283. doi:10.1037/0022-3514.56.2.267

Costa, P. T., \& Mc Crae, R. R. (1985). The NEO personality inventory manual. Odessa, FL: Psychological Assesment Resources, Inc.

Derogatis, L. R. (1994). Administration, scoring and procedures. Manual III (3rd ed.). Minneapolis, MN: National Computer Systems.

Diener, E. (1984). Subjective well-being. Psychological Bulletin, 95, 542-575. doi:10.1037/0033-2909.95.3.542

Diener, E., Emmons, R. A., Larsen, R. J., \& Griffin, S. (1985). The satisfaction with life scale. Journal of Personality Assessment, 49, 71-76. doi:10.1207/s15327752jpa4901 13

Dunkley, D. M., Zuroff, D. C., \& Blankstein, K. R. (2003). Self-Critical perfectionism and daily affect: Dispositional and situational influences on stress and coping. Journal of Personality and Social Psychology, 84, 234-252. doi:10.1037/0022-3514.84.1.234

Endler, N. S., \& Parker, J. D. A. (1990). Multidimensional assesment of coping: A critical evaluation. Journal of Personality and Social Psychology, 58, 844-854. doi:10.1037/0022-3514.58.5.844

Endler, N. S., \& Parker, J. D. A. (1999). Coping Inventory for Stressful Situations (CISS): Manual. Toronto: Multi-Health Systems.

Erikson, E. H. (1968). Identity: Youth and crisis. New-York: Norton.

Folkman, S., Lazarus, R. S., Dunkel-Schetter, C., DeLongis, A., \& Gruen, R. J. (1986). Dynamics of a stressful encounter: Cognitive appraisal, coping, and encounter outcomes. Journal of Clinical Psychology, 48, 589-595.

Garner, D. M., \& Garfinkel, P. E. (1979). The eating attitudes test: An index of the symptoms of anorexia nervosa. Psychological Medicine, 9, 273-279. doi:10.1017/S0033291700030762

Garner, D. M., Olmsted, M. P., Bohr, Y., \& Garfinkel, P. E. (1982). The eating attitudes test: Psychometric features and clinical correlates. Psychological Medicine, 12, 871-878. doi: $10.1017 / \mathrm{S} 0033291700049163$

Grebot, E., \& Barumandzadeh, T. (2005). L'accès à l'Université: Une situation stressante à l'origine de certaines stratégies d'ajustement dysfonctionnelles. (French). Annales Medico Psychologiques, 163, 561-567. doi:10.1016/i.amp.2004.07.015

Halamandaris, K. F., \& Power, K. G. (1997a). Individual differences, dysfunctional attitudes, and social support: A study of the psychosocial adjustment to university life of home students. Personality \& Individual Differences, 22, 93-104. doi:10.1016/S0191-8869(96)00175-4 
Halamandaris, K. F., \& Power, K. G. (1997b). Individual differences, dysfunctional attitudes, and social support: A study of the psychosocial adjustment to university life of home students. Personality and Individual Differences, 22, 93-104. doi:10.1016/S0191-8869(96)00175-4

Hammer, A. L. (1988). Manual for the coping ressources inventory. Palo Alto, CA: Consulting Psychologists Press.

Hatchett, G. T., \& Park, H. L. (2004). Relationships among optimism, coping styles, psychopathology, and counseling outcome. Personality \& Individual Differences, 36, 1755.

doi:10.1016/j.paid.2003.07.014

Janzen, B. L., Kelly, I. W., \& Saklofske, D. H. (1992). Bulimic symptomatology and coping in a nonclinical sample. Perceptual and Motor Skills, 75, 395-399. doi:10.2466/pms.1992.75.2.395

Jessor, R., Chase, J. A., \& Donovan, J. E. (1980). Psychosocial correlates of marijuana use and problem drinking in a national sample of adolescents. American Journal of Public Health, 70, 604-613. doi:10.2105/AJPH.70.6.604

Keniston, K. (1971). Youth and dissent: The rise of a new opposition. New York: Harcourt Brace Jovanovich.

Khantzian, E. J. (1985). The self-medication hypothesis of addictive disorders: Focus on heroin and cocaine dependence. American Journal of Psychiatry, 142, 1259-1264.

Kline, P. (1993). Handbook of psychological testing. London: Routledge.

Kraemer, H. C., \& Thiemann, S. (1987). How many subjects? Statistical power analysis in research. Newbury Park: Sage.

Lafay, N., Manzanera, C., Papet, N., Marcelli, D., \& Senon, J. L. (2003). Les états dépressifs de la post-adolescence. Résultats d'une enquête menée chez 1521 étudiants de l'université de Poitiers. Annales Medico Psychologiques, 161, 147. doi:10.1016/S0003-4487(03)00021-0

Lazarus, R. S., \& Folkman, S. (1984). Stress, appraisal and coping. New York: Springer.

Levinson, D. J. (1978). The seasons of a man's life. New York: Ballantine.

Mayhew, R., \& Edelmann, R. J. (1989). Self-esteem, irrational beliefs and coping strategies in relation to eating problems in a non-clinical population. Personality and Individual Differences, 10, 581-584. doi:10.1016/0191-8869(89)90042-1

Paxton, S. J., \& Diggens, J. (1997). Avoidance coping, binge eating and depression: An examination of the escape theory of binge-eating. International Journal of Eating Disorders, 22, 83-87.

Roger, D., Jarvis, G., \& Najarian, B. (1993). Detachment and coping: The construction and validation of a new scale for measuring coping strategies. Personality and Individual Differences, 15, 619-626. doi:10.1016/0191-8869(93)90003-L

Rolland, J. P., Parker, W. D., \& Stumpf, H. (1998). A psychometric examination of the French translations of the NEO-FFI. Journal of Personality Assessment, 71, 269-292. doi:10.1207/s15327752jpa7102 13

Rosenberg, M. (1969). Conceiving the self. New York, Basic Books. Stewart, S. M., Betson, C., Lam, T. H., Marshall, I. B., Lee, P. W. H., \& Wong, C. M. (1997). Predicting stress in first year medical students: A longitudinal study. Medical Education, 31, 163-168. doi:10.1111/j.1365-2923.1997.tb02560.x

Towbes, L. C., \& Cohen, L. H. (1996). Chronic stress in the lives of college students: Scale development and prospective prediction of distress. Journal of Youth and Adolescence, 25, 199-217. doi:10.1007/BF01537344

Vitaliano, P. P., Russo, J., Carr, J. E., Maiuro, R. D., \& Becker, J. (1985). The ways of coping checklist: Revision and psychometric properties. Multivariate Behavioral Research, 20, 3. doi:10.1207/s15327906mbr2001 1

Vollrath, M. (1998). Smoking, coping and health behavior among university students. Psychology \& Health, 13, 431-441. doi:10.1080/08870449808407301

Wauquiez, L. (2006). Les aides aux étudiants et leurs conditions de vie: Comment relancer l'ascenceur social ? Rapport ministérielle, juillet 2006.

Wills, T. A. (1986). Stress and coping in early adolescence: Relationships to substance use in urban school samples. Health Psychology, 5, 503-529. doi:10.1037/0278-6133.5.6.503

Wills, T. A., \& Shiffman, S. (1985). Coping and substance use: A conceptual framework. In S. Shiffman, \& T. A. Wills (Eds.), Coping and substance use. San Diego: Academic Press. 